Revista de Estudios Histórico-Jurídicos

[Sección Historia del Pensamiento Jurídico]

XXXV (Valparaíso, Chile, 2013)

[pp. 681 - 706]

\title{
LAS BASES FILOSÓFICAS DE LA DOCTRINA PENAL de ThOMas HobBes
}

[Philosophical Grounds of the Criminal Doctrine of Thomas Hobbes]

\author{
Carlos Isler Soto* \\ Universidad Bernardo O’Higgins, Santiago, Chile \\ Universidad Diego Portales, Santiago, Chile
}

\section{RESUMEN}

La teoría penal de Thomas Hobbes presenta doctrinas que parecen incompatibles entre sí, y por ello son interpretadas diversamente en la actualidad. El trabajo quiere demostrar que Hobbes sostiene doctrinas aparentemente contradictorias porque se siguen de supuestos más básicos acerca de la naturaleza del ser humano y de la razón práctica.

Palabras Clave

Thomas Hobbes - Ley penal - Castigo - Prevención general - Determinismo - Culpabilidad.

\section{Abstract}

The criminal theory of Thomas Hobbes presents doctrines that seem to be incompatible and, for this reason, they have several interpretations nowadays. This work aims at demonstrating that Hobbes maintains apparently contradictory doctrines, because they are $b$ ased on basic assumptions about the na ture of the human being and of practical reasoning.

\section{KEYWORDS}

Thomas Hobbes - Criminal law - Punishment - General prevention - Determinism - Guilt.

RECIBIDO el 19 de abril y ACEPTADO el 26 de julio de 2013

* Licenciado en Ciencias Jurídicas y Sociales por la Universidad Austral de Chile. Licenciado en Filosofía por la Universidad de los Andes. Candidato a Doctor en Derecho en Pontificia Universidad Católica de Chile. Profesor de Filosofía del Derecho en la Universidad Bernardo O'Higgins, y de Derecho y Moral en la Universidad Diego Portales. Dirección postal: Coronel Pereira 140, departamento 101, Las Condes, Chile. Correo electrónico: carlos_isler@yahoo.com 


\section{INTRODUCCIÓN}

Thomas Hobbes es conocido, ante todo, como filósofo político. El autor del Leviathanes asociado normalmente con la tesis de la generación de la comunidad política mediante un contrato social, la defensa del absolutismo político y del erastianismo, de la obligación de someterse incondicionalmente al derecho y la negación de todo derecho a resistencia de los súbditos. Sin embargo, Hobbes fue un autor extremadamente prolífico y de inquietudes muy diversas: escribió también sobre filosofía de la naturaleza, filosofía del hombre, ética, estética, lógica, óptica, filosofía de la matemática, historia y derecho, además de traducir clásicos griegos al inglés. Poca atención se había prestado a varios de dichos temas hasta hace muy poco, pero recientemente han comenzado a surgir estudios que ponen de relieve tales facetas. Así, los estudiosos han comenzado a poner atención también a su doctrina penal.

El pensamiento jurídico de Hobbes se inserta dentro y depende de su pensamiento político. Hobbes elabora una teoría del derecho dependiente de una teoría política destinada a justificar la existencia de la comunidad política y la obligación de obedecer siempre a su gobernante, el "soberano" -salvo el caso muy excepcional del peligro de la vida del súbdito por la obediencia al soberano-. Así, dentro de sus obras políticas, Hobbes trata no sólo temas relativos a la teoría del derecho en general, sino también temas específicos de dogmática jurídica, como la teoría del contrato, de la representación, derecho sucesorio y del derecho penal. Todos dichos tópicos son objeto de estudio de Hobbes en cuanto son funcionales a su teoría política: así, su teoría del contrato se desarrolla para explicar el surgimiento de la comunidad política mediante un contrato de todos los súbditos entre sí; desarrolla una teoría de la representación, para explicar la naturaleza de la relación entre soberano y súbditos; el derecho sucesorio deviene tema de su exposición cuando debe explicar qué sucede cuando muere un soberano y, finalmente, expone los temas fundamentales del derecho penal en cuanto éste es el instrumento principal que posee el soberano para mantener la paz en la república.

Así como el tratamiento de dichos temas depende de su teoría política, ésta depende de supuestos filosóficos más generales. En el presente trabajo, pretendemos exponer el modo como la doctrina penal de Hobbes y, particularmente, su rechazo del retribucionismo, dependen de tales supuestos filosóficos.

\section{LOS SUPUESTOS ANTROPOLÓGICOS}

DE LA FILOSOfía POlítica de Thomas Hobbes

No se entiende la idea hobbesiana de que la república se genera mediante un pacto social, si no se entiende el modo como concibe al hombre. El así llamado “pesimismo antropológico” hobbesiano no es más que la consecuencia de ciertas tesis filosóficas más fundamentales.

\section{El egoísmo sicológico.}

Ante todo, para Hobbes el hombre es un ser sicológicamente egoísta, vale decir, un animal que por necesidad natural busca, en toda acción, conseguir un bien para 
sí. Si persigue algún bien para otro, lo hace necesariamente porque el que otro consiga tal bien es parte de su propio bien. El bien ajeno no puede ser querido en cuanto tal, y así lo expresa en todas sus obras políticas: en Elements of Law ${ }^{1}$, De cive $e^{2}$ y Leviathan ${ }^{3}$. De este modo reinterpreta todas las reacciones humanas a partir del egoísmo: así, la caridad o buena voluntad tiene su origen en el deseo de apreciar el propio poder, en este caso, de ayudar a los demás ${ }^{4}$; el llanto que acompaña normalmente a la reconciliación entre dos personas está causado, piensa Hobbes, "por la detención súbita causada a sus pensamientos de venganza"; la piedad es causada por la "imaginación de que una calamidad tal pueda acontecerle a uno mismo" ". La concepción hobbesiana queda muy bien graficada en una anécdota transmitida por John Aubrey, el primer biógrafo de Hobbes: según cuenta Aubrey, cuando Hobbes, un teólogo y él mismo se encontraron con un mendigo, Hobbes le dio a éste una limosna. Le preguntó el teólogo: “¿Habrías realizado esto, si no fuese el mandato de Cristo?'. 'Sí', dijo él. - ‘¿Por qué?' preguntó el otro.- 'Porque', dijo, 'sufría al considerar la miserable condición del anciano; y ahora mi limosna, al darle a él cierto alivio, también me calma a mí”’

Cuando Hobbes expone que el hombre sea naturalmente egoísta, no quiere

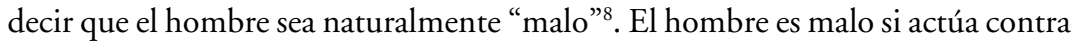
el deber; bueno, si actúa conforme al deber y por mor del deber. Así, el hombre, además de entender qué sea lo beneficioso, puede entender qué sea lo debido. Tal

${ }^{1}$ Hobbes, Thomas, Elements of Law. Human Nature and De Corpore Politico (New York, Oxford University Press, 2008) [en adelante, "Elem."; se citará indicando, primero, si se trata de la primera parte o de la segunda (Human Nature y De Corpore Politico, respectivamente), a continuación, indicará el capítulo, el parágrafo y la página. Así, Elem. I,XVI,7, p. 90, significa que el texto se encuentra en la primera parte de la obra (Human Nature), capítulo XVI, parágrafo 7, página 90]. Elem. I,XIV,6, pp. 78-79: "necessity of nature maketh men to wil and desire bonum sibi, that which is good for themselves, and to avoid that which is hurtful"; Elem. I, XV, 1, p. 81: "we intend always our own safety and preservation"; Elem. I,XVI, 5, p. 90: "For by necessity of nature every man doth in all his voluntary actions intend some good unto himself".

${ }^{2}$ Hobbes, Thomas, De Cive (Oxford, Oxford University Press, 1983) [en adelante, "DC.", que se citará indicando capítulo, parágrafo y página. Así, DC. III,12, p. 113, indica que el texto citado se encuentra en el capítulo III, parágrafo 12, página 113]. DC. I, VII, p. 94: "Fertur enim vnusquisque ad appetitionem eius quod sibi Bonum, \& ad Fugam eius quod sibi malum est, maximè autem maximi malorum naturalium, quae est mors; idque necessitate quadam naturae, non minore quam quâ fertur lapis deorsum"; DC. I, XIII, pp. 96-97: "nam vnusquisque naturali necessitate bonum sibi appetit".

${ }^{3}$ Hobbes, Thomas, Leviathan (Oxford, Oxford University Press, 2012) [en adelante, "Lev.", que se citará indicando el capítulo y la página. Así, Lev. XVIII, p. 276, indica que el texto citado se encuentra en el capítulo XVIII, página 276]. Lev. XIV, p. 202: "of the voluntary acts of every man, the object is some Good to himselfe".

${ }^{4}$ Elem. I,IX,17, p. 56: "There is yet another passion sometimes called love, but more properly good will or Charity. There can be no greater argument to a man of his own power, than to find himself able, not only to accomplish his own desires, but also to assist other men in theirs: and this is that conception wherein consisteth charity".

${ }^{5}$ Lev. VI, p. 88.

${ }^{6}$ Lev. VI, p. 90.

${ }^{7}$ Aubrey, John, The Brief Life, en Elem., p. 242.

${ }^{8}$ En consecuencia, el término "egoísta" aquí no tiene una connotación peyorativa. 
como la anécdota transcrita muestra, Hobbes cree que un ser egoísta puede ser benefactor de otros y, en consecuencia, "bueno", aunque lo que busque en cada acción sea siempre algún bien para sî".

\section{El carácter insaciable del deseo humano.}

El hombre no sólo desea el bien para sí de modo necesario: su deseo es, además, insaciable. Con ello, Hobbes pretende oponerse a las teorías éticas clásicas, que comenzaban por identificar un fin último de la acción humana, y a ordenar las acciones y demás fines en relación a tal fin para determinar qué sea lo correcto. Paradigma de este modelo es le Ética a Nicómaco de Aristóteles, que se inicia, precisamente, discutiendo cuál sea el fin último del hombre.

Para Hobbes, en cambio, no hay tal fin último, porque, de haberlo, el deseo humano podría ser saciado: "la Felicidad de esta vida no consiste en el reposo de una mente satisfecha. Pues no existe tal finis ultimus (objetivo final) ni summum bonum (sumo bien) tal como se habla en los Libros de los viejos Filósofos Morales. Ni puede un hombre cuyos Deseos han finalizado vivir más que aquél cuyos Sentidos e Imaginación están inertes. La Felicidad es un continuo progreso del deseo, de un objeto a otro; no siendo el alcanzar el primero sino el camino al segundo" ${ }^{\prime \prime}$.

\section{La insaciable sed de poder del hombre.}

Una tercera tesis antropológica fundamental del filósofo de Malmesbury es aquella que sostiene que en el hombre se da una insaciable sed de poder. Si en toda acción el hombre busca un bien para sí, necesariamente, por coherencia desiderativa, al tiempo que desea el bien, debe desear los medios que le permitan alcanzar tal bien. Estos medios son el poder $^{11}$. Y se desea el poder de modo insaciable, no sólo porque el deseo humano en general es insaciable, sino también porque no puede asegurarse la posición actual propia sin tener más poder que el

\footnotetext{
${ }^{9}$ Sobre las razones por las cuales Hobbes cree que el hombre es naturalmente egoísta hay opiniones diversas en la literatura especializada. ZARKA, Yves, La décision métaphysique de Hobbes. Conditions de la politique (Paris, Vrin, 2009), p. 228; y RHONHeIMER, Martin, La filosofia politica di Thomas Hobbes (Roma, Armando, 1997), p. 112., creen que es consecuencia de su teoría del conocimiento sensista y fenomenista. Brown, Stuart, Hobbes: the Taylor Thesis, en The Philosophical Review, 68 (1959) 3, p. 322. piensa que las aserciones que enuncian la doctrina del egoísmo sicológico son meras tautologías estipuladas con el fin de justificar, mediante una larga cadena de razonamientos, junto a otras premisas, la obligación de obedecer incondicionalmente al derecho. Una opinión totalmente distinta es la de ZAGorin, Perez, Hobbes and the Law of Nature (Princeton, Princeton University Press, 2009), p. 102, quien cree que, en realidad, el egoísmo de Hobbes no es sicológico, sino tautológico (en un sentido diverso al expresado por Brown): Hobbes, con las aserciones citadas, sólo querría dar a entender que el hombre desea por necesidad lo que desea.

${ }^{10}$ Lev. XI, p. 150. Véase, igualmente: Elem. I,VIII,6, p. 44: "But for an utmost end, in which the ancient philosophers have placed felicity, and have disputed much concerning the way thereto, there is no such thing in this world, nor way to it, more than to Utopia: for while we live, we have desires, and desire presupposeth a farther end".

${ }^{11}$ Lev. X, p. 132: "The Power of a Man, (to take it Universally,) is his present means, to obtain some future apparent Good".
} 
de su potencial adversario. Si usted tiene $\mathrm{X}$ unidades de poder, y su adversario tiene $\mathrm{X}+1$, entonces su adversario puede quitarle el bien que usted actualmente posee. De ahí que sea necesario buscar tener siempre más poder que los demás: tener poder es tener más poder que los otros. "De modo que, en primer lugar, supongo como inclinación general de toda la humanidad, un deseo perpetuo e incesante de Poder tras poder, que cesa sólo con la muerte"12.

\section{La igualdad natural de todos los hombres.}

Un cuarto supuesto antropológico es el de la igualdad natural de poder de todos los hombres. Igualdad natural de poder no significa que todos los hombres tengan exactamente el mismo poder. Es un hecho patente que hay personas más fuertes o inteligentes que otras. Significa, más bien, que no importando cuánto más fuerte o inteligente sea una persona respecto de otra, la segunda siempre podrá causar a la primera el mayor de los males: la muerte. Igualdad natural de los hombres significa, en consecuencia, que cualquiera tiene, naturalmente, el poder de matar a cualquiera ${ }^{13}$.

\section{El carácter físicamente necesitado de toda acción humana.}

Hobbes no cree en la libertad de la voluntad. Su determinismo deriva de dos fuentes: su ontología materialista y su teoría de la causalidad, que identifica la causa suficiente con la necesaria. Sobre su ontología, es sabido que Hobbes cree que todo lo que existe son cuerpos en movimiento. La noción de sustancia inmaterial es, según piensa, absurda. Incluso Dios es cuerpo ${ }^{14}$. Y todo cuerpo se rige por las leyes necesarias de la física. De ahí que todo movimiento de un ser corpóreo, como el hombre, se deba a causas físicas necesarias anteriores en el tiempo ${ }^{15}$. Esto

${ }^{12}$ Lev. XI, p. 150.

${ }^{13}$ Véase, al respecto, L, XIII, p. 188. Esta característica del hombre, su capacidad de matar a otro, cualquiera que éste sea, ha sido expresada de modo más claro por HART, H.L.A., The Concept of Law (Oxford, Oxford University Press, 1994), p. 195, en su claramente hobbesiana doctrina del contenido mínimo del Derecho natural: "Approximate equality. Men differ from each other in physical strength, agility, and even more in intellectual capacity. None the less it is a fact of quite major importance for the understanding of different forms of law and morality, that no individual is so much more powerful than others, the he is able, without co-operation, to dominate or subdue them for more than a short period. Even the strongest must sleep at times and, when asleep, loses temporarily his superiority. This fact of approximate equality, more than any other, makes obvious the necessity for a system of mutual forbearance and compromise which is the base of both legal and moral obligation".

${ }^{14}$ Sobre esto, véase : Weber, Dominique, Hobbes et le corps de Dieu (Paris, Vrin, 2009).

${ }^{15}$ Con bastante consecuencia, Hobbes extiende esto incluso a Dios: ni siquiera Dios goza de libre albedrío, simplemente porque la noción de libre albedrío es, piensa, absurda. Por esto, son erradas las interpretaciones que inscriben a Hobbes dentro de la tradición voluntarista teológica, como: Damrosch, Leopold, Hobbes as Reformation Theologian: Implications of the Free-Will Controversy, en Journal of the History of Ideas, 40 (1979) 3, p. 343: "Hobbes's theology embraces a total voluntarism”; ibíd., p. 351: “Hobbes would not want to accept Spinoza's identification of creator and creation. Natura naturans and Nattura naturata, and would assert against Spinoza that God is free in the sense of being able to perform arbitrary or undetermined actions". Esta interpretación, como muestra FOISNEAU, Hobbes et la toute-puissance de Dieu (Paris, 
incluye sus voliciones: la voluntad, en la doctrina hobbesiana, no es una facultad distinta de los apetitos sensibles, el llamado "apetito intelectual" por la tradición clásica. No: en el hombre sólo se dan apetitos sensibles (desde que todo lo que existe y, consecuentemente, es apetecible, es corpóreo y, por lo tanto, sensible), de modo que la voluntad no es sino el último apetito que precede a la acción, el último acto en la deliberación.

En efecto: antes de cada acción tendemos a sopesar las razones a favor y en contra de la misma, "y diversas consecuencias, buenas y malas, de hacer u omitir la cosa propuesta vienen sucesivamente a nuestros pensamientos, de modo que a veces tenemos un Apetito de ella, y a veces una Aversión de ella; algunas veces Esperanza de poder hacerla, algunas veces Desesperanza, o miedo de intentarla; la suma total de Deseos, Aversiones, Esperanzas y Miedos, continuadas hasta que la cosa, o es hecha, o es considerada imposible, es lo que llamamos 'deliberación'”'16.

Pero como la deliberación es una sucesión de apetitos y aversiones, también lo encontramos en las bestias. Y si las bestias deliberan, también tienen voluntad, porque la voluntad no es sino "el último Apetito o Aversión adherido a la acción, o a la omisión de la misma"17. La voluntad es acto, no facultad. De ahí que "la definición de la 'voluntad' dada comúnmente por las Escuelas, esto es, un apetito racional, no es buena. Porque si lo fuese, no podría haber Acto voluntario alguno contra la razón"18.

Conviene aclarar esto bien: Hobbes no niega que el hombre pueda querer algo: lo que niega es que lo quiera lo quiera libremente. De ahí que, si una persona desea algo malo, Hobbes piensa que tal persona es culpable, por haber querido aquello que quiso. Sólo que lo que quiso, lo quiso necesariamente ${ }^{19}$.

Presses Universitaires de France, 2000), atenta contra la evidencia textual: en su polémica con Bramhall, Hobbes dice expresamente que Dios no puede hacer nada distinto de lo que hace.

${ }^{16}$ Lev. VI, p. 90.

${ }^{17}$ Lev. VI, p. 90,

${ }^{18}$ Lev. VI, p. 92.

${ }^{19}$ Conviene dejar esto claro, porque hay quienes, como Cattaneo, Mario, Hobbes e il fondamento del diritto di punire, en SorgI, Giuseppe (editor), Politica e Diritto in Hobbes (Milano, Giuffrè, 1995), pp. 132-133, que creen que Hobbes, al negar el libre albedrío, está sosteniendo una teoría objetiva de la responsabilidad penal, en cuanto elimina el elemento culpabilidad del delito: "da un lato Hobbes sostiene il determinismo, e afferma quindi che l'azione del colpevole è necessitata; dall'altro egli osserva que il carattere necessitato dell'azione non influisce sulla giustizia della punizione, unicamente perché quest'ultima serve a intimidire gli altri. È questo un típico esempio di dottrina della prevenzione generale che si concentra unicamente sulla funzione dell'esempio, e non tiene assolutamente in nessun conto il problema dell'imputabilità, della misura della responsabilità personale, in sostanza di ciò che il colpevole ha realmente 'meritato'. L'impostazione hobbesiana conduce veramente a trattare il colpevole come un mero mezzo nell'interesse della società, a porre la sua azione (in quanto necessitata) sul piano di qualsiasi azione dannosa naturale, e tuttavia a punirlo, semplicemente perché la sua punizione è utile per l'intimidazione e prevenzione generale; è una posizione che giustifica perfettamente la critica di Kant". Hobbes cree, en cambio, que al delincuente se lo castiga por ser culpable, esto es, por haber querido realizar el delito, y por eso trata también sobre las causales de atenuación o exención de la responsabilidad penal. En ese sentido, no se desinteresa por lo que el delincuente realmente "merezca”, y no trata al delito como una acción natural más. Sí cree, en cambio, que el querer fue necesitado -porque un evento no necesitado por otro anterior es, según Hobbes, 
Ahora bien: ¿qué evento es el que necesita la producción de la acción humana libre? Hobbes cree que es la representación de un bien mayor que cualquier otro a alcanzar mediante, o la abstención, o mediante una acción alternativa ${ }^{20}$. Esto tendrá importancia para la determinación de la cuantía de la pena asignada a un delito por el legislador.

\section{ORIGEN DEL ESTADO Y DE LA SOBERANÍA}

\section{Derecho y ley natural.}

Como es sabido, Hobbes es conocido por ser uno de los primeros teóricos importantes del llamado "contractualismo", esto es, aquella doctrina que sostiene que el origen de la comunidad política se encuentra en un hipotético contrato social. La doctrina del contractualismo, y la teoría penal de ella dependiente, derivan totalmente de las premisas antropológicas supuestas por Hobbes. Si el hombre es un ser naturalmente egoísta, con un deseo insaciable, una sed de poder también insaciable, y además con la misma capacidad de causar la muerte a otro, ¿cuál sería la situación en la que se encontraría si no hubiese un poder coercitivo

impensable-. De ahí que sea discutible lo que agrega CATTAneo, ibíd., p. 133: "La concezione di Hobbes al riguardo è assimilabile a quella di taluni studiosi inglesi contemporanei, che sostengono la legittimità dell'intervento dello Stato, sia pure non con la pena ma con una 'terapia sociale', anche per atti dannosi compiuti con 'responsabilità oggetiva', cioè né con dolo né con colpa. In entrambi i casi non si tiene per nulla conto dell'elemento intenzionale [...]”. Hobbes sí tiene en cuenta el elemento intencional, y estaría totalmente en desacuerdo con la idea de una responsabilidad sin culpa. Lo que sí cree es que la culpa o el dolo son físicamente necesitados por eventos anteriores. Por supuesto, se puede sostener con Kant, y nosotros estamos totalmente de acuerdo, que la noción de responsabilidad moral es inconsistente con cualquier determinismo, de modo que la doctrina de Hobbes es, finalmente, inconsistente. Del mismo modo, se puede sostener, también con Kant, que el egoísmo sicológico es incompatible con la creencia en algo así como una obligación moral, y también estamos de acuerdo con ello. Lo anterior sólo muestra inconsistencias en la teoría hobbesiana, pero no que Hobbes no haya creído realmente en la existencia de algo así como la ley moral o la culpabilidad moral y jurídica. Por eso, podemos coincidir con Cattaneo, ibíd., p. 139. cuando afirma que en la doctrina penal hobbesiana hay un conflicto "fra gli aspetti positivi, dati dalla affermazione della certeza del diritto, sia pure con alcune eccezioni, e da una serie di limiti posti alla funzione penale, e gli aspetti negativi, dati suprattuto dall'atribuzione alla pena dello scopo primario della prevenzione generale, e dalla coniugazione di questa con l'ipotesi deterministica".

${ }^{20}$ Téngase presente el siguiente pasaje de HobBes, Thomas, Of Liberty and Necessity, en Chappel, Vere (editor) Hobbes and Bramhall on Liberty and Necessity (Cambridge, Kindle, 2003), parágrafo 3, en el que disputa con el obispo Bramhall: "And the first place of Scripture, taken from Numbers XXX. 13, is one of those that look another way. The words are, If a wife make a vow, it is left to her husband's choice either to establish it or make it void.' For it proves no more but that the husband is a free and voluntary agent, but not that his choice therein is not necessitated or not determined to what he shall choose by precedent necessary causes. For if there come into the husband's mind greater good by establishing than by abrogating such a vow, the establishing will follow necessarily; and if the evil that will follow thereon in the husband's opinion outweigh the good, the contrary must needs follow":. Hobbes dice que el marido es un agente libre y voluntario, pero ello no debe inducir a error: su concepto de libertad no consiste en el haber tenido el agente la posibilidad de actuar de otro modo, sino en no estar impedido el agente de actuar por impedimentos externos. De ahi que pueda decir que "choosing and necessity are joined together". 
que lo controlase? La respuesta es conocida: sería, necesariamente, una situación de guerra de todos contra todos. La descripción que Hobbes hace de tal estado, al que en Elements of Law y De cive llama "estado de naturaleza", y en el Leviathan, "condición original de la humanidad", se ha hecho famosa: "Por consiguiente, todo aquello que es consiguiente a un tiempo de Guerra, en el cual cada hombre es enemigo para cada hombre, eso mismo es consiguiente al tiempo en el cual los hombres viven sin ninguna otra seguridad que la que les otorgará su propia fuerza y su propio ingenio. En tal condición no hay lugar para la Industria, pues su fruto es incierto; y consiguientemente, ningún cultivo de la tierra; ninguna Navegación, ni uso de las comodidades que puedan ser importadas por el mar; ningún edificio confortable; ningún instrumento para mover y remover aquellas cosas para las que se requiera mucha fuerza; ningún conocimiento de la faz de la tierra; ningún cómputo del tiempo; ningún arte; ningunas letras, ninguna sociedad; $y$, lo que es peor de todo, miedo continuo y peligro de una muerte violenta; Y la vida del hombre, solitaria, pobre, repugnante, brutal y corta" 21 .

Hobbes piensa que, en tal situación, ninguna acción que realizase el sujeto para protegerse -y la protección incluye el ataque preventivo, con el fin de evitar un ataque posterior del otro- sería injusta. Todo sujeto tendría, en tal estado, "derecho a todo", entendiendo por tal el derecho a realizar cualquier acción que el sujeto, según su propio juicio, sirva para asegurar su supervivencia. Incluso la muerte o mutilación de otros. La razón es sencilla: desde que el hombre por naturaleza desea su propio bien, y la vida es el supuesto de la consecución de cualquier otro bien, por coherencia desiderativa no puede no desear sobrevivir. Y si desea sobrevivir, no es contrario a la razón que realice cualquier acto con tal fin, desde que el objeto necesario de su deseo es su bien individual.

Así, el derecho natural o derecho más básico del ser humano "es la Libertad que tiene cada hombre para usar su propio poder, tal como desee, para la preservación de su propia Naturaleza; es decir, de su propia vida y, consiguientemente, de hacer cualquier cosa que, según su propio juicio y razón, conciba como los medios más aptos para ello"22.

Por otro lado, "una ley de la naturaleza (lex naturalis) es un precepto, o regla general, descubierta por la razón, por la cual a un hombre se le prohíbe hacer

${ }^{21}$ Lev. XIII, p. 192

${ }^{22}$ Lev. XIV, p. 198. Por su parte, define libertad del siguiente modo: "By liberty, is understood, according to the proper signification of the word, the absence of externall Impediments: which Impediments, may oft take away part of a mans power to do what hee would; but cannot hinder him from using the power left him, according as his judgement and reason shall dictate to him". Ahora bien: es claro que hay cierta inconsistencia en la definición hobbesiana por lo siguiente: define libertad como una ausencia física de impedimentos, y al derecho natural como una libertad, pero el derecho natural no puede ser la mera ausencia física de impedimentos, porque implica legitimidad de lo que se hace. La definición de derecho natural no debería decir "ausencia de impedimentos exteriores", sino "la necesidad de que otros no pongan impedimentos externos al ejercicio de los actos exteriores del sujeto". De lo contrario, de entender que el derecho es una libertad física, se seguría que, verbigracia, quien se encuentra atrapado en un lugar del que no puede salir, al tener restringida su libertad física, también es afectado en su derecho natural, lo que es absurdo si nadie conoce de su situación ni lo ha puesto en ella. 
aquello que es destructivo para su vida, o quite los medios para preservar la misma; y omitir aquello que piense que la preservará del mejor modo"23. De modo que ley y derecho son incompatibles sobre lo mismo, desde que la ley impone obligación y el derecho, en cambio, es una libertad.

Ahora bien: en el estado de naturaleza todos tienen derecho a todo, y precisamente ello es lo que causa que la situación del hombre sea tan miserable en el estado de naturaleza. Pero aunque la naturaleza ha puesto al hombre en tal desdichada situación, ella misma le ha dado los medios para salir de ella: su razón y sus pasiones ${ }^{24}$. "Las pasiones que inclinan al hombre a la paz son: el miedo a la muerte; el deseo de las cosas necesarias para una vida cómoda; y la Esperanza de obtenerlas por su Industria. Y la razón sugiere artículos de paz convenientes, bajo los cuales los hombres puedan llegar a un acuerdos. Estos artículos son aquellos que de otro modo han sido llamados las Leyes de la Naturaleza"25.

Pues bien: dado que la razón ordena realizar aquello que sirve a la conservación de la existencia, el primer precepto práctico de la misma ordenará lo siguiente: "Que cada hombre debe ("ought") intentar la paz, en cuanto tenga esperanza de obtenerla; y cuando no pueda obtenerla, que ha de buscar y usar todas las ayudas y ventajas de la guerra" ${ }^{26}$.El primer precepto es disyuntivo: ordena una cosa $\mathrm{u}$ otra, según sea posible la paz o no. El fin de la razón es siempre el mismo: la autoconservación, pero los medios para lograrla son distintos según si la paz es posible o no. Hobbes agrega: "La primera parte de esta regla contiene la primera y fundamental ley de la naturaleza; la cual es buscar la paz y seguirla. la segunda, la suma del derecho de la naturaleza, el cual es, defendernos por todos los medios posibles"27.

Ahora bien: dado que lo que causa la situación miserable en el estado de naturaleza es el derecho de todos a todo, y que la primera ley de la naturaleza ordena buscar la paz, y rige si es que hay esperanza de alcanzar la paz, entonces, habiendo tal esperanza, rige la segunda ley de la naturaleza, derivada de la primera: "De esta ley fundamental de la naturaleza, por la cual se manda a los hombres ("by which men are commanded') buscar la paz, se deriva esta segunda ley; Que un hombre esté dispuesto, cuando otros también lo estén, tanto como lo considere necesario para la paz y su defensa, abandonar su derecho a todas las cosas; y contentarse con tanta libertad contra otros hombres, cuanta permitiría a otros hombres contra si mismo" 28 . La tercera ley de la naturaleza es el "pacta sunt servanda".

A continuación, Hobbes procede a derivar 19 leyes de la naturaleza a partir de la primera y fundamental. La justificación de todas ellas consiste en que, de no seguir el comportamiento por ellas prescrito, el ser humano volvería a la situación

${ }^{23}$ Lev. XIV, p. 198.

${ }^{24}$ Lev. XIII p. 196: "And thus much for the ill condition, which man by meer Nature is actually placed in; though with a possibility to come out of it, consisting partly in the Passions, partly in his Reason".

${ }^{25}$ Lev. XII, p. 196.

${ }^{26}$ Lev. XIV, p. 200.

${ }^{27}$ Ibíd.

${ }^{28}$ Ibíd. 
miserable de guerra en la que se encuentra en el estado de mera naturaleza. Todas ellas se justifican, en último término, en atención al autointerés del sujeto. Lo importante, para nuestro tema, es lo siguiente: es ordenado por la ley de la naturaleza renunciar al derecho a todo; de lo contrario, el fin de la supervivencia se hace difícil de alcanzar: si todos tienen derecho a todo, entonces se produce una situación en la que estoy en perpetuo peligro. Para salir de tal situación, se debe renunciar al derecho a todo, y tal cosa sólo puede hacerse si se crea un poder coercitivo, capaz de poner coto a los impulsos agresivos de las personas, de modo que se cree una comunidad donde antes había un mero agregado de individuos. Tal poder coercitivo es el Estado, el soberano es su titular, y el derecho, su instrumento.

Por último, y esto es particularmente importante para entender el estatus de la ley penal: las leyes de la naturaleza son leyes morales, que obligan en conciencia. Se debe cumplir con lo dispuesto por ellas de modo incondicionado ${ }^{29}$. Aun si algunas de ellas mandan bajo condición -v.gr., se debe buscar la paz bajo condición de que ésta sea posible-, dicha condición no depende de la voluntad del sujeto -si se da, se debe, inexorablemente, buscar la paz-- Por ello, son, en terminología kantiana, imperativos categóricos ${ }^{30}$. Hobbes deja muy claro en el De cive que, para que una acción sea moralmente buena, se requiere no sólo la adecuación de la conducta a la ley natural, sino la realización de dicha conducta porque la ley natural lo exige: "estos nombres, justo e injusto (iustum \& iniustum), tal como justicia e injusticia (iustitia \& iniustitia), son equívocos; pues significan una cosa cuando se atribuyen a las personas, y otra cuando se atribuyen a las acciones. Cuando se atribuyen a las acciones, justo significa lo mismo que un hecho conforme a Derecho (iure factum); e injusto lo mismo que daño (iniuria). Pero quien hace algo justo, no es llamado justo, sino inocente ("insons"); y llamamos culpable ("sons") y no injusto a quien ha realizado algo injusto. Cuando se usa en relación a las personas, ser justo significa lo mismo que gozar haciendo lo justo (iuste faciendo), buscar la justicia o intentar realizar en todas las cosas aquello que es justo. Y ser injusto es desatender la justicia, o pensar que se ha de determinar no mediante el propio pacto, sino mediante la comodidad presente. De modo que una cosa es la justicia e injusticia de la mente, de la institución o del hombre, y otra cosa distinta la de una acción u omisión particular; innumerables acciones del hombre justo pueden ser injustas, y del injusto, justas. Pues se llama justo al hombre que hace las cosas justas por el precepto de la ley (propter preceptum legis), y cosas injustas sólo por

${ }^{29}$ Por supuesto, esto puede ser inconsistente con el rechazo hobbesiano de la libertad de la voluntad. Tal como expresa Kant, si se debe realizar una acción, se la debe poder realizar, de modo que sostener que se debe realizar una acción prescrita por la ley de la naturaleza y, al mismo tiempo, sostener que quien actuó contra ella lo hizo de modo necesario, es un contrasentido.

${ }^{30}$ Según la distinción kantiana, lo que diferencia a un imperativo hipotético de uno categórico es que el primero manda bajo condición de que se desee un fin, y el categórico no. Dicha condición depende del sujeto. Pero un imperativo que mandase bajo otra condición no dependiente del sujeto -que se de un supuesto de hecho-, puede ser categórico. Por ejemplo, cumplir con imperativo "dar limosna alguna vez a un pobre" depende de que exista un pobre, pero no deja de ser categórico. Kant muestra lo anterior cuando dice que la ley penal es un imperativo categórico, aunque, obviamente, su aplicación depende del supuesto de hecho de que se dé un delito. 
debilidad (per infirmitatem); injusto es aquél que hace cosas justas a causa de la pena adjunta a la ley, e injustas, por la iniquidad de su mente" ${ }^{31}$. Como diría Kant, quien actúa moralmente bien actúa conforme al deber y por deber. También el soberano, a quien obligan estas leyes naturales ${ }^{32}$.

\section{Origen del Estado.}

Así, salir del estado de naturaleza, algo que la propia razón prescribe, supone la formación de un pacto entre todos los hombres en orden a obedecer a un tercero, formando así una comunidad política. En el Leviathan, recurrirá a la teoría de la representación para explicar el contenido del pacto por el que se origina el Estado, y la relación jurídica existente entre soberano y súbditos. Así, una "Persona es aquél cuyas palabras o acciones son consideradas, ya como sus propias, ya como representando las palabras o acciones de otro hombre, o de alguna otra cosa a la cual son atribuidas, ya sea verdaderamente o mediante ficción.

Cuando son consideradas como suyas propias, entoncesse le llama una persona natural: Y cuando son consideradas como representando las palabras o acciones de otro, entonces es una persona fingida o artificial' ${ }^{\text {'3 }}$.

Ahora bien: "de las personas artificiales, en algunas, sus palabras y acciones son Hechas propias por aquellos a quienes representan. Y entonces la persona es el actor; y aquél que se apropia de palabras o acciones, es el autor: en cuyo caso el actor actúa por autoridad"34. De este modo, la autoridad no es sino "el derecho a hacer alguna acción" ("Right of doing any act"/ius agendi). La autoridad implica que quien detenta la misma tiene un derecho subjetivo a actuar de un modo determinado a nombre de otro. Ahora bien: el representante tiene autoridad porque el representado se la ha dado, de modo que la autoridad tiene límites: aquéllos que haya puesto el representado al momento de conferir autoridad o capacidad de representarlo a otro. Y cuando el representante actúa dentro de dichos límites, obliga al representado, el autor, tanto como si hubiese actuado él mismo.

¿Cómo se instituye esta comunidad? Mediante un pacto recíproco de sumisión

${ }^{31}$ DC. III,V, p. 110.

${ }^{32}$ Asimismo, existe, como es sabido, discusión entre los estudiosos acerca de si estas leyes naturales son, en el pensamiento de Hobbes, mandatos divinos -tal como expresa en diversos pasajes-, de modo que no pueda entenderse que obligasen, que sean leyes morales, a menos de ser considerados como tales. La discusión está lejos de terminar; no se ha llegado a ningún consenso y parece improbable que se llegue a alguno. Defensores de la interpretación "teísta" de la ley natural en Hobbes son, por ejemplo: TAYLOR, A. E., The Ethical Doctrine of Hobbes, en Philosophy, 13, 52 (1938), pp. 406-424; MarTinich, Aloysius, The Two Gods of Leviathan. Thomas Hobbes on Religion and Politics (Cambridge, Cambridge University Press, 1992). En contra, sosteniendo la normatividad moral independiente de un mandato divino, por parte de las leyes naturales: Boвbio, Norberto, La teoria politica di Hobbes (1980), ahora en EL MISMO, Thomas Hobbes (Torino, Einaudi, 2004), pp. 27-72-; Brown, Stuart, (n. 8); RHONHEIMER, Martin, cit. (n. 9); SADLER, Gregory The Laws of Nature as Moral Norms in Hobbes' Leviathan, en Acta Philosophica, 15 (2006) 1, pp. 77-94; y, por supuesto, STrauss, Leo, Hobbes'politische Wissenschaft in ihrer Genesis (1936), después en EL MISMO, Hobbes politische Wissenschaft und zugehörige Schriften (Stuttgart, J. B. Metzler, 2008), quien, además, cree que fue ateo.

${ }^{33}$ Lev. XVI, p. 244.

${ }^{34}$ Ibid. 
a un tercero: "el único modo de erigir tal poder común, que pueda ser capaz de defenderlos de la invasión de extranjeros, y de las agresiones del uno al otro, y de este modo asegurarlos de tal manera que puedan alimentarse y vivir satisfechos por su propia industria y por los frutos de la Tierra, es conferir todo su poder y fuerza a un hombre, o a una asamblea de hombres, que puedan reducir todas sus voluntades, por pluralidad de voces, a una sola voluntad: lo cual es lo mismo que decir: designar a un hombre, o asamblea de hombres, a portar su persona; y que cada uno haga propio, y se reconozca a sí mismo como autor de cualquier cosa que haga o cause que se haga aquél que porte de este modo su persona, en aquellas cosas que se refieran a la paz y seguridad común; y, con ello, someter cada uno de ellos sus voluntades a su voluntad, y sus juicios, a su juicio. esto es más que consentimiento, o concordia: es una unidad real de todos ellos en una y la misma persona, creada por pacto de cada hombre con cada hombre de tal modo, como si cada hombre hubiese de decir a cada hombre, autorizo y abandono mi derecho a gobernarme a mí mismo a éste hombre, o asamblea de hombres, bajo esta condición, que tú abandones tu derecho a él, y autorices todas sus acciones del mismo modo. una vez hecho esto, la multitud unida de este modo en una persona, es llamada república (“common-wealth”), en latín, civitas. Esta es la generación de aquel gran Leviathan, o más bien (para hablar de un modo más reverente) de aquel dios mortal, al cual debemos, bajo el dios inmortal, nuestra paz y defensa. Pues por esta Autoridad dada a él por cada hombre particular en la República, se le ha conferido el uso de tanto poder y fuerza, que está capacitado para conformar las voluntades de todos ellos, a la paz en el interior, y a la ayuda mutua contra sus enemigos en el exterior. y en él consiste la esencia de la república; la cual (para definirla) es una persona, de cuyos actos una gran multitud se ha hecho cada uno el autor por pactos mutuos uno con otro, con el fin de que pueda usar la fuerza y medios de todos ellos, tal como él considere conveniente, para su seguridad y defensa común" 35 .

El estado surge así de la necesidad de obtener la seguridad que no existe en el estado de naturaleza. Sin embargo, su fin no es solamente preservar la existencia física de sus miembros. Por ello es creado, además, y desde el inicio, para permitir llevar una vida confortable ${ }^{36}$. Es necesario que los individuos, al celebrar tal pacto, renuncien a su derecho a realizar cualquier acción. Sin embargo, piensa Hobbes, aunque se renuncie al derecho a todo, esto no implica una sumisión incondicional al titular del poder creado (el soberano): dado que el fin para el cual se crea el Estado y la soberanía es la protección del sujeto, cuando alguna orden del soberano ponga en peligro la vida del sujeto, éste se encontrará legitimado para resistirla. El derecho no es un pacto suicida, y esto es particularmente

${ }^{35}$ Lev. XVII, p. 260-262.

${ }^{36}$ Elem. I,XIX,8, p. 107: "This union so made, is that which men call now-a-days a body politic or civil society; and the Greeks call it pólis, that is to say, a city; which may be defined to be a multitude of men, united as one person by a common power for their common peace, defence and benefit". En el Leviathan, según se recordará, dice que lo que mueve a los hombres a salir del estado de naturaleza son las pasiones del miedo a la muerte, el deseo de comodidades, y la esperanza de obtenerlas por su trabajo. 
claro en Hobbes, si se tiene en cuenta, además, que una vez asumido el egoísmo sicológico resulta conceptualmente imposible suponer algo así como una obligación de matarse o dejarse matar. Toda acción realizada por un sujeto tiene como objeto necesario su bien propio. También la celebración del pacto por el que se crea la comunidad. Eso significa que se compromete a obedecer sólo en cuanto la obediencia no ponga en peligro su bien propio -sería sicológicamente imposible obligarse a más que eso-, y precisamente porque un estado en el que todos obedecen a un tercero le resulta provechoso. Pero cuando tal estado no le resulte provechoso, estará legitimado para resistirse. Esto explicará la conocida, y para muchos extraña, doctrina hobbesiana del derecho del delincuente condenado a resistir la imposición de la pena.

\section{EL DERECHO A CASTIGAR}

Se decía que el soberano es la persona que detenta el poder del Estado ${ }^{37}$. Tiene derecho a actuar representando a sus súbditos, de modos que éstos han de considerar lo hecho por él como si lo hubiesen hecho ellos mismos. Ahora bien: el soberano es quien tiene aquél poder tan necesario para la conservación de la paz social como es el derecho a castigar. ¿Cuál es el fundamento de aquél derecho? Hobbes no puede afirmar, sin más, que el soberano tenga derecho a castigar a algún súbdito porque éste se lo haya dado: no puede otorgarse aquel derecho ${ }^{38}$. El súbdito, al momento de ser castigado, no puede considerar la orden de castigarlo como procedente de sí: el objeto necesario de toda acción humana es el bien propio. Y, sin embargo, el soberano debe tener derecho a castigar: sin tal derecho, la creación del Estado sería inútil.

El fundamento del derecho a castigar del soberano no es otro que el mismo

${ }^{37}$ El soberano, para Hobbes, no necesariamente debe ser unipersonal: si lo es, el régimen vigente es una monarquía; si es una pequeña cantidad de hombres, es una aristocracia; y si la mayoría, una democracia. En este último caso, soberana es la asamblea conformada por tales hombres. No hay en Hobbes defensa a ultranza de la monarquía, aunque sí la considera el mejor régimen de gobierno. ( $\mathrm{Al}$ menos en su etapa más conocida: si se acepta la atribución a Hobbes $\operatorname{del} A$ Discourse upon the Beginning of Tacitus, de 1620, aparecido junto a otros dos textos: $A$ Discourse of Laws y $A$ Discourse of Rome, en una obra anónima llamada Horae subsecivae. En este escrito de juventud Hobbes habría manifestado que un estado monárquico no es un estado libre. Véanse: HobBes, Thomas, A Discourse upon the Beginning of Tacitus, en EL MISMO, Three Discourses. A Critical Modern Edition of Newly Identified Work of the Young Hobhbes (Chicago, the University of Chicago Press, 1995, edición a cargo de Noel Reynolds y Arlene Saxenhouse), pp. 38, 39 y 45). De ahí que, aunque Hobbes haya sido un defensor del absolutismo político, no lo fue de la monarquía absoluta, y ello lo diferencia de Jacobo I o Robert Filmer. Debe dejarse claro que la atribución del Discourse upon the Beginning of Tacitus a Hobbes es dudosa, ante todo por el carácter anónimo del libro en el que aparecieron los tres discursos -junto a otros no atribuidos a Hobbes-. Así, por ejemplo, ForTIER, John, "A Discourse of Laws": The Perils of Wordprint Analysis, en The Review of Politics, 59 (1997) 4, pp. 861-887, pone en duda tal atribución, y especialmente la del Discourse of Laws.

${ }^{38}$ Lev. XXVIII, 482: "It is manifest therefore that the Right which the Common-wealth (that is, he, or they that represent it) has to Punish, is not grounded on any concession, or gift of the Subjects". 
derecho a todo que tenía en el estado de naturaleza. En palabras del propio Hobbes: "he mostrado también que, anteriormente, antes de la Institución de la República, cada hombre tenía un derecho a cualquier cosa, y a hacer cualquier cosa que considerase necesaria para su propia preservación; subyugar, herir o matar a cualquier hombre con tal fin. y este es el fundamento de aquel derecho a castigar que es ejercitado en toda república. pues los súbditos no dieron tal derecho al soberano; sino que sólo, al renunciar al suyo, fortalecieron a éste para usar el suyo, tal como lo considerase necesario, para la preservación de todos ellos: de modo que no le fue dado, sino dejado, y a él solo; y (exceptuando los límites que le impone la ley natural) tan íntegro, como en la condición de mera naturaleza, y de guerra de cada uno contra su vecino" ${ }^{39}$. Así, el derecho a todo del estado de naturaleza deviene, en el caso del soberano, en el derecho a castigar. En el estado de naturaleza no hay castigo ${ }^{40}$ : puede haber retribución de mal por mal, pero no castigo. El derecho a castigar surge con el Estado: es un modo del derecho a todo del estado de naturaleza: el modo que adquiere en el soberano de una comunidad política.

Pero el soberano no sólo tiene el derecho de castigar: tiene también el deber de hacerlo. Y tal deber es un deber moral. En efecto: el soberano se encuentra sujeto a las leyes morales. Que los súbditos no puedan cuestionar sus órdenes no implica que éstas puedan ser arbitrarias: el soberano se encuentra sujeto siempre a las leyes de la naturaleza, aun cuando ningún súbdito pueda discutir si éste ha dado cumplimiento a los requerimientos de éstas o no.

\section{LA MEDIDA DEL CASTIGO: PERDÓN Y SANCIÓN}

Se decía que el soberano tiene el deber de castigar. Y para determinar la medida del castigo, debe atender al bien que mediante él pueda lograrse. A similitud de Kant, Hobbes piensa que la ley penal es un imperativo categórico. Con todo, a diferencia de él, la ley penal no existe para castigar un delito por el mero hecho de que se haya cometido: sirve para retribuir mal por mal en cuanto tal retribución es beneficiosa para la sociedad. El soberano está moralmente obligado a hacer aquello que sea beneficioso para la sociedad -lo que coincide con aquello que es beneficioso para sí mismo, piensa Hobbes-: como consecuencia de ello, está moralmente obligado a castigar, aplicando tanto mal al delincuente cuanto sea necesario para preservar la paz social. Las leyes que prescriben realizar lo beneficioso para sí mismo -que, en el caso del soberano, equivalen a lo beneficioso para la sociedad-, son las leyes naturales. Y dentro de éstas, es la séptima la que prescribe la magnitud del daño a retribuir: "que en las venganzas, (esto es, la retribución de mal por mal,) los hombres no se fijen tanto en la magnitud del daño pasado, sino en la magnitud del bien que seguirá. Por la cual se nos prohíbe infligir castigo con

${ }^{39}$ Ibíd.

${ }^{40}$ Lev. XIV, 214: "in the condition of Nature, where every man is Judge, there is no place for Accusation". Sobre esto, véase: SCHROCK, Thomas S., The Rights to Punish and Resist Punishment in Hobbes's Leviathan, en The Western Political Quarterly, 44 (1991) 4, pp. 858-859. 
algún otro fin que para la corrección del ofensor, o la dirección de otros. Pues esta ley es consiguiente a la inmediatamente anterior a ella, que manda el perdón, bajo seguridad del tiempo futuro. además, la venganza sin consideración al ejemplo y beneficio que se siga, es un triunfo o gloriarse en el daño a otro, que no tiende a ningún fin (pues el fin es siempre algo futuro); y gloriarse sin fin alguno, es vanagloria, y contrario a la razón; y dañar contra la razón tiende a la introducción de la guerra; lo que, nuevamente, es contrario a la ley de la naturaleza; y es comúnmente calificado con el nombre de crueldad '¹. Así, aunque el soberano se encuentre obligado a castigar -la ley penal es un imperativo categórico-, el fundamento de tal obligación es que, mediante la pena, se alcanza un bien futuro. Una posición como la kantiana, piensa Hobbes, es cruel.

Pero la imposición del castigo es condicional: supone que no se den las condiciones expuestas por la anterior ley de la naturaleza: "que bajo caución del tiempo Futuro, un hombre debe perdonar las ofensas pasadas a aquéllos que, arrepentidos, lo deseen. Pues el perdón no es sino el garantizar la paz; la cual, si se garantiza a aquellos que perseveran en su hostilidad, no es paz, sino miedo; pero si no es garantizada a aquellos que dan caución para el tiempo Futuro, es signo de aversión a la Paz; y, consiguientemente, contrario a la ley de la naturaleza" 42 .

Vale decir: el mandato que debe seguir el soberano se enunciaría de modo completo así: supuestoque no se pueda perdonar al ofensor, se debe aplicar una pena al mismo cuya medida será el bien futuro a obtenerse mediante la misma; si se puede perdonar, se debe hacer, supuesta caución por parte del ofensor. Ese mandato es un imperativo categórico ${ }^{43}$.

${ }^{41}$ Lev. XV, p. 232. Véase igualmente: DC. III,XI, p. 113.

${ }^{42}$ Lev. XV, p. 232.

${ }^{43}$ Esto generará algunos problemas en lo relativo a la doctrina teológica del infierno: si todo castigo mira a la consecución de un bien futuro, no parece tan claro cómo sea posible un castigo eterno, cuando ya no será posible redención ni será necesaria amenaza alguna para que el hombre se abstenga de actuar mal. En Elements of Law y De Cive, Hobbes resuelve el problema diciendo que la imposición de la pena eterna es un castigo impuesto antes del pecado, con miras al bien futuro de la salvación: Elem. I, XVIII,11, p. 102: "Concerning revenge which by the law of nature ought not to aim, as I have said chapter XVI, section 10, at present delight, but at future profit, there is some difficulty made, as if the same accorded not with the law divine, by such as object the continuance of punishment after the day of judgment, when there shall be no place, neither for amendment, nor for example. This objection had been of some force, if such punishment had been ordained after all sins were past; but considering the punishment was instituted before sin, it serveth to the benefit of mankind, because it keepeth men in peaceable and virtuous conversation by the terror; and therefore such revenge was directed to the future only". Véase igualmente: DC. IV,IX, p. 125. En esto, su exposición se asemeja a la de la tradición católica. Véase al respecto: Thoma Aquinat., Summa Theologiae I-II, q. 87, a. 3, ad 2, quien, cuando defiende la eternidad de las penas del infierno, respondiendo a la objeción de que la pena debe tener un carácter medicinal, y no se ve cómo el castigo eterno pueda tener dicho carácter, expresa que "poena etiam quae secundum leges humanas infligitur, non semper est medicinalis ei qui punitur, sed solum aliis, sicut cum latro suspenditur, non ut ipse emendetur, sed propter alios, ut saltem metu poenae peccare desistant; secundum illud Prov. XIX, pestilente flagellato, stultus sapientior erit. Sic igitur et aeternae poenae reproborum a Deo inflictae, sunt medicinales his qui consideratione poenarum abstinent a peccatis". En ambos casos, el de Hobbes y Tomás, hay una separación de la tradición anterior que consideraba que era de la esencia de la pena ser medicinal respecto del condenado, de modo que a éste le convenía ser 
$Y$, ¿por qué es beneficiosa a la sociedad la imposición del castigo? En la séptima ley de la naturaleza, Hobbes expresa que mediante la imposición del castigo se puede alcanzar, o la rehabilitación del delincuente, o la disuasión respecto a los demás ciudadanos. Pero en general, Hobbes se concentra se concentra sólo en la función preventivo general de la ley penal ${ }^{44}$. Ello es particularmente claro cuando, en su polémica con el obispo Bramhall, se refiere a las críticas que éste había hecho a su determinismo, en cuanto parece cruel castigar a quien no ha podido actuar de otro modo. La respuesta de Hobbes muestra claramente su concepción de la ley penal como ordenándose sobre todo a la disuasión de los ciudadanos: "Por ejemplo, supongamos que la ley prohibiese, bajo pena de muerte, el robar, y hubiese un hombre que, por la fuerza de su tentación fuese necesitado a robar y es, por ello, condenado a muerte; ¿̨no detiene su castigo a otros? ¿No es causa de que otros no roben? ¿No ordena y dirige sus voluntades hacia la justicia? Crear tal ley es, consiguientemente, crear una causa de justicia y necesitar la justicia; y, consiguientemente, no es injusticia crear tal ley" ${ }^{45}$.

Pues bien: si la función de la ley penal es disuadir, entonces se entenderá que haya de cumplir con dos desiderata importantísimos: su carácter escrito y no retroactivo.

En efecto: si la función de la ley penal es disuadir, sólo puede cumplir dicha función si es previamente conocida por los súbditos. De ahí que no pueda existir delito sin ley previa. Hobbes suscribe el principio "nullum crimen sine lege ${ }^{346}$, pero

castigado: cfr Platón, Gorgias, 472e. En el Leviathan, XLIV, pp. 988-990, Hobbes, en cambio, ya no creerá en la eternidad de las penas del infierno, por parecerle tal doctrina, "dura", de modo que procederá a reinterpretar los pasajes de las Escrituras que se refieren al mismo.

${ }^{44}$ CatTANEO, cit. (n. 19), pp. 128-129: "nelle conseguenze tratte dalla definizione di pena, si palesa anche l'idea della prevenzione speciale (cioè lo spingere il delinquente a obbedire, in futuro, alla legge). Ma il motivo che mi sembra fondamentale e prevalente nel pensiero di Hobbes, in quanto si manifesta in tutti i brani ora considerati, e che solo è presente nella definizione stessa data nel Leviathan, è l'idea dell'intimidazione o prevenzione generale".

${ }^{45}$ Véase en Of Liberty and Necessity, cit. (n. 20), parágrafo 14 el siguiente pasaje: "men are not therefore put to death or punished for that their theft proceeds from election, but because it was noxious and contrary to men's preservation; and the punishment conducing to the preservation of the rest, inasmuch as to punish those that do voluntary hurt, and none else, frames and makes men's wills such as men would have them": También su definición de castigo en Lev. XXVIII, p. 482: "A Punishment, is an Evill inflicted by publique Authority, on him that hath done, or omitted that which is Judged by the same Authority to be a Transgression of the Law; to the end that the will of men may thereby the better be disposed to obedience".

${ }^{46}$ Pero, entiéndase bien: "ley" aquí incluye la ley natural. En efecto: Hobbes sostiene que, para que exista delito se requiere que exista derecho positivo: "Civill Law ceasing, Crimes cease: for there being no other Law remaining but that of Nature, there is no place for Accusation": Lev. XXVII, p. 454. En el estado de naturaleza, donde sólo rige la ley natural, no hay castigo. Sin embargo, una vez instituido el Estado, la ley natural rige también supletoriamente a la ley positiva. Así, en el estado político, puede haber castigo de transgresiones a la ley natural: "Ignorance of the Law of Nature Excuseth no man; because every man that hath attained to the use of Reason, is supposed to know, he ought not to do another, what he would not have done to himself. Therefore into what place soever a man shall come, if he do anything contrary to that Law, it is a Crime": Lev. XXVII, pp. 454-456. Más aún: dicha ley natural es "eterna e inmutable": "The Lawes of Nature are Immutable and Eternall; for Injustice, Ingratitude, Arrogance, Pride, Iniquity, Acception 
no el "nulla poena sine lege" ${ }^{\text {"47 }}$ : el filósofo de Malmesbury cree que basta con que una ley prohíba una acción, sin especificar la pena que castiga su transgresión, para que tal ley pueda cumplir su función disuasiva.

Pero, y esto es particularmente importante, no es la sola existencia de la ley lo que disuade: es su aplicación constante y de manera coherente por los tribunales, pues "siempre que aparece la esperanza de impunidad, sus efectos proceden" 48 .

\section{LA MEDIDA DEL CASTIGO: LAS SANCIONES COMO PRECIOS}

El soberano está obligado a castigar, dados ciertos supuestos de hecho. También debe establecer los castigos de modo previo, atendiendo al bien futuro que se

of persons, and the rest, can never be made lawfull. For it can never be that Warre shall preserve life, and Peace destroy it": Lev. XV, p. 240. Y, en el mismo capítulo XXVII, que trata sobre los delitos, expone que "where Law ceaseth, Sinne ceaseth. But because the Law of Nature is eternal, Violation of Covenants, Ingratitude, Arrogance, and all Facts contrary to any Morall virtue, can never cease to be Sinne": Lev. XXVII, p. 454. Más claro todavía es el párrafo en el que se enuncia expresamente el principio "nullum crimen sine lege": "No Law, made after a Fact done, can make it a Crime: because if the Fact be against the Law of Nature, the Law was before the Fact; and a Positive Law cannot be taken notice of, before it be made; and therefore, cannot be Obligatory": Lev. XXVII, p. 458. Igualmente, en Lev. XXVII, p. 468: "only Children, and Madmen are Excused from offences against the Law Natural". Conviene tener lo anterior en cuenta para captar por qué son erradas muchas interpretaciones de Hobbes como un "formalista" en materia penal. Véase, por ejemplo, lo que expresa Hermosa AndúJAR, Antonio, La doctrina penal de Hobbes, en Fragmentos de Filosofía, 6 (2008), pp. 84-85: "Al delimitar el ámbito del delito con la acción, y al fijar como referente suyo la ley -la ley civil, la única digna de ese nombre...- el concepto secularizado de delito se vuelve también formalista [...]. El comportamiento delictivo por sí mismo no existe en Hobbes, pues presupondría la existencia de un mal absoluto por sí mismo al que aquél tendiera voluntariamente en lugar de hacerlo frente a su natural antagonista: el bien absoluto... La institución del Estado pondría término a ese ciclo natural, suplantando la inexistencia de un bien absoluto natural con la creación de un bien absoluto convencional: las leyes [...]./ Así pues, lo malo no ha sido legalmente prohibido por ser malo; lo malo es legalmente malo por haber sido prohibido. Violar la ley es delito; y ninguna otra cosa, salvo es, es delito". Ahora, si bien es efectivo que Hobbes cree que, donde no hay ley, no hay delito, y que es la prohibición por la ley la que confiere el carácter delictivo a una acción, deja bien claro que: i) la ley natural, en el estado político, rige supletoriamente a la ley civil y ésta puede y debe castigar las transgresiones a aquélla; ii) la ley natural, a la que llama también ley moral, sí prohíbe de modo absoluto e invariable ciertos comportamientos, precisamente por referencia a un mal absoluto, que Hobbes afirma expresamente que existe: la muerte. Véase: DC. I,VII, p. 94: "Fertur enim vnusquisque ad appetitionem eius quod sibi Bonum, \& ad Fugam eius quod sibi malum est, maximè autem maximi malorum naturalium, quae est mors; idque necessitate quadam naturae, non minore quam quâ fertur lapis deorsum".

${ }^{47}$ Lev. XXVII, p. 456: "Ignorance of the Penalty, where the Law is declared, Excuseth no man: For in breaking the Law, which without a fear of penalty to follow, were not a Law, but vain words, he undergoeth the penalty, though he know not what it is; because, whosoever voluntarily doth any action, accepteth all the known consequences of $i$; but Punishment is a known consequence of the violation of the Lawes, in every Common-wealth; which punishment, if it be determined already by the Law, he is subject to that; if not, then he is subject to Arbitrary punishment. For it is reason, that he which does Injury, without other limitation than that of his own Will, should suffer punishment without other limitation, than that of his Will whose Law is thereby violated".

${ }^{48}$ Ibíd., p. 462. 
alcance mediante el castigo. Ahora bien: el soberano, cuando pueda perdonar, debe hacerlo. No debe establecer castigos que sobrepasen lo necesario para disuadir a los posibles delincuentes, pero tampoco debe establecer penas cuya representación no disuada al posible delincuente de delinquir. La labor del soberano es una de difícil equilibrio, de búsqueda de un justo medio entre crueldad e indulgencia ${ }^{49}$.Y es que, piensa Hobbes, el soberano debe establecer penas capaces de disuadir porque, de lo contrario, por necesidad los seres humanos habrán de delinquir. Si el egoísmo sicológico, la insaciable sed de poder, el carácter insaciable del deseo humano y la igualdad natural de todos los hombres justifican la necesidad de instaurar un poder castigador, el egoísmo sicológico y el carácter necesario de toda acción humana justifica la necesidad de que el mal infligido con la pena haya de ser, al menos, superior al bien que el posible delincuente pretenda alcanzar mediante el delito. De otro modo, piensa Hobbes, es imposible que puedan disuadir: "el castigo previamente conocido, si no es lo suficientemente grande como para detener a los hombres de la acción, es una invitación a ella: pues cuando los hombres comparan el beneficio de su Injusticia con el daño de su castigo, por necesidad de Naturaleza escogen aquello que parece mejor para sí mismos: $y$, por consiguiente, cuando son castigados más que aquello que la Ley haya previamente determinado, o más de lo que otros fueron castigados por el mismo Crimen, es la ley la que los tienta y los engaña" ${ }^{50}$. Y, es que piensa Hobbes, todo hombre es un posible delincuente. Así como, en el estado de naturaleza, necesariamente todo hombre se convierte en lobo para el hombre, asimismo, en el estado social, si el daño asociado como pena a una ley que prohíbe una acción no es mayor que el beneficio que el sujeto puede obtener mediante la acción prohibida, dicho sujeto por necesidad de naturaleza -toda acción humana es necesitada por eventos antecedentes- realiza dicha acción, dicho sujeto deviene necesariamente delincuente. Todo hombre es un posible delincuente y, supuestas ciertas condiciones, deviene necesariamente uno -no hay libertad de la voluntad-. Del mismo modo que todo hombre es un posible lobo para los demás y, supuestas ciertas condiciones, deviene necesariamente uno. Es este carácter necesario de toda acción humana y el egoísmo sicológico lo que permite, piensa Hobbes, establecer medidas adecuadas para las penas. Si el hombre tuviese libre albedrío - noción que Hobbes considera absurda en sí misma-, no podría establecerse la magnitud de la pena de modo racional.

Con ello, Hobbes se acerca muchísimo a los análisis de la medida de la pena realizados por la corriente contemporánea llamada "Análisis económico del Derecho". Es sabido que los autores de dicha corriente pretenden aplicar los métodos de la ciencia económica, precisos y cuantificables, al análisis de la realidad jurídica. En el caso del derecho penal, supuesto fundamental de dicho análisis es que el posible delincuente considera la pena como el "precio" que ha

${ }^{49} \mathrm{Si}$ Aristóteles podía exclamar que es difícil ser bueno, precisamente porque ser bueno implica tener una razón práctica que acierte siempre respecto del justo medio entre dos vicios extremos, Hobbes podría exclamar "es difícil ser soberano", dado que el soberano debe encontrar siempre un difícil justo medio entre una pena excesiva, que no es pena sino acto de hostilidad, y una pena indulgente, que no es pena sino precio del delito.

${ }^{50}$ Lev. XXVII, p. 456. 
de pagar si se quiere obtener un bien ${ }^{51}$. Si se quiere que no se realice una acción determinada, se debe establecer un "precio" -pena- mayor que el precio del bien a obtener mediante dicha acción, de modo que el posible delincuente, en tanto sea un agente económico racional, decida no realizar dicha acción en cuanto la relación costo-beneficio de dicha realización sea desventajosa.

Y eso es, precisamente, lo que sostiene Hobbes: cuando analiza la magnitud del castigo, dice expresamente que si el daño en que éste consista no es mayor que el beneficio a obtener mediante la realización de la acción prohibida, entonces tal daño no es realmente castigo, sino un precio a pagar por el agente: "Si el daño infligido es menor que el beneficio o contento que naturalmente sigue al crimen cometido, tal daño no entra en la definición [de castigo]; y es más bien el precio o el valor, más que el castigo de un crimen: pues es de la naturaleza del castigo el tener por fin el disponer a los hombres a obedecer la ley; fin que (si es menor que el beneficio de la transgresión) no alcanza, sino que produce el efecto contrario" ${ }^{22}$.

Sin embargo, pese al anticipo hobbesiano de tal análisis económico de la motivación del delincuente, hay diferencias importantes. Dado que para Hobbes el fin principal de la pena es la disuasión, sostiene que debe establecerse y aplicarse una pena consistente en un daño mayor al beneficio esperado, a menos que nos encontremos frente a los supuestos que exigen el perdón, sin tomar en consideración otras variables. En cambio, Becker sostiene que la determinación de la pena debe ser función de muchas variables, tales como los costos del delito mismo, de la mantención del sujeto en la cárcel, del juicio y del arresto ${ }^{53}$. Y es que, a diferencia de Hobbes, que pone como fin del derecho penal la disuasión, Becker cree que el fin del derecho penal es la minimización del costo social. Dicho fin incluye, entre otros, a la disuasión ${ }^{54}$.

${ }^{51}$ Véase el seminal trabajo de BECKER, Gary, Crime and Punishment: An Economic Approach, en Journal of Political Economy, 76 (1968) 2, pp. 176-177: "The approach taken here follows the economists' usual analysis of choice and assumes that a person commits an offense if the expected utility to him exceeds the utility he could get by using his time and other resources at other activities. Some persons become 'criminals', therefore, not because their basic motivations differs from that of other persons, but because their benefits and costs differ [...]. This approach implies that there is a function relating the number of offenses by any person to his probability of conviction, to his punishment if convicted, and to other variables, such as the income available to him in legal and other illegal activities, the frequency of nuisance arrests, and his willingness to commit an illegal act".

${ }^{52}$ Lev. XXVIII, p. 484.

${ }^{53}$ Véase: BECKER, cit. (n. 51), p. 191: "[...] if the costs of apprehending, convicting, and punishing offenders were nil and if each offense caused more external harm tan private gain, the social loss from offenses would be minimized by setting punishments high enough to eliminate all offenses. Minimizing the social loss would become identical with the criterion of minimizing crime by setting penalties sufficiently high", énfasis añadido. Hobbes nunca se pregunta por los costos de captura, enjuiciamiento y castigo de los delincuentes. De ahí que, para él, se debe siempre establecer y aplicar penas suficientemente altas como para disuadir al delincuente.

${ }^{54}$ Ibíd., p. 208: "Vengeance, deterrence, safety, rehabilitation, and compensation are perhaps the most important of the many desiderata proposed troughout history. Nex to these, minimizing the social loss in income may seem narrow, bland, and even quaint... Yet one should not lose sight of the fact that it is more general and powerful than it may seem and actually includes more dramatic desiderata as special cases". Otras diferencias importantes son, primero que Becker 
Así, la consideración de la disuasión como fin del derecho penal, y la creencia en el carácter necesario de la acción criminal si es que la pena no es lo suficientemente disuasiva de la acción indeseable, lleva a que Hobbes no descarte, en principio, ninguna de las penas aplicadas en su época, algunas de las cuales hoy podrían parecer crueles. Las penas, expone, pueden ser corporales, pecuniarias, la ignonimia, prisión, exilio, o una mezcla de todas ellas. Dentro de las corporales, "algunas son capitales, otras menos que capitales. Capital es la inflicción de la muerte; y ésta, ya simplemente, ya con tormento. Menos que capitales son stripes, heridas, cadenas, y cualquier otro dolor corporal que no sea mortal en su naturaleza" ${ }^{55}$.

\section{CUlPabilidad PENAL}

La negación del libre albedrío no implica en Hobbes la desaparición de la noción de culpabilidad. Hobbes niega la libertad de la voluntad, pero no la existencia de la misma. La voluntad, en Hobbes, no es una facultad desiderativa, como en la tradición clásica, sino el último apetito que precede a la acción. La voluntad es, así, acto: es el querer realizar la acción.

La noción de castigo implica la de culpabilidad: se es castigado porque se quiso realizar la acción prohibida, no sólo por haber realizado una acción que produce un resultado nocivo. Así, el determinismo no lleva a Hobbes a rechazar la noción de culpabilidad: más bien a modificarla. En efecto: aunque se castiga a quien es culpable por un acto voluntario suyo, la noción de culpabilidad hobbesiana -en esto reside su novedad-, no incluye la idea de exigibilidad de otra conducta. El culpable es castigado porque quiso hacer lo que hizo, aun cuando no haya podido querer algo distinto a aquello que quiso -todo evento en el mundo es necesitado por causas anteriores en el tiempo-.

Que Hobbes entiende que la noción de culpabilidad está incluida en la de castigo, queda claro cuando trata de las eximentes y atenuantes de responsabilidad

no asume una sicología egoísta: BECKER, Gary, Nobel Lecture: The Economic Way of Looking at Behavior, en The Journal of Political Economy, 101 (1993) 3, pp. 385-386: "Unlike Marxian analysis, the economic approach I refer to does not assume that individuals are motivated solely by selfishness or material gain. It is a method of analysis, not an assumption about particular motivations. Along with others, I have tried to pry economists away from narrow assumptions about self-interest. Behavior is driven by a much richer set of values and preferences./ The analysis assumes that individuals maximize welfare as they conceive it, whether they be selfish, altruistic, loyal, spiteful, or masochistic". Segundo, que su análisis de las causas del delito es bastante más complejo que el de Hobbes, quien cree que la ocurrencia de uno se encuentra causado sólo por el carácter insuficiente de la pena para disuadir o la poca probabilidad prevista de ser apresado o condenado. Becker, en cambio, sostiene que los factores que inciden en la cantidad de delitos son más variados, e incluyen la educación, especialización y la cantidad de empleos legales: véase BECKER, ibíd., p. 390.

${ }^{55}$ Lev. XXVIII, p. 488. Sin embargo, rechaza la tortura como medio de prueba en juicio, por considerarla un medio de prueba ineficaz para descubrir la verdad, dado que el torturado dirá cualquier cosa que se le diga que ha de decir, con tal de liberarse del dolor; véase: Lev. XIV, p. 214. 
penal ${ }^{56}$ : excusan de la responsabilidad penal la ignorancia de la ley civil cuando ésta no ha sido suficientemente declarada por el soberano ${ }^{57}$, la ignorancia del derecho en el caso del extranjero ${ }^{58}$, la defensa propia ${ }^{59}$, el estado de necesidad ${ }^{60}$. Todo lo anterior lleva a rechazar la idea, propuesta por Cattaneo, de que en Hobbes exista algo así como una defensa de la responsabilidad penal objetiva. Más todavía, cuando sostiene que es ilícito castigar al inocente ${ }^{61}$.

\section{EL DERECHO A RESISTIR EL CASTIGO}

Se decía que el derecho a castigar no lo entregan los súbditos al soberano, porque ello es sicológicamente imposible. Más aun: los hombres renuncian a su derecho a todo en el estado de naturaleza, con el fin de preservar su integridad mediante la constitución del Estado. Se obligan a obedecer al representante de éste, pero dicha obediencia es condicional: en tanto sirva a los fines que se tuvieron en mente para instituir Estado y soberano. Cuando el soberano, mediante su actuación, ponga en peligro la vida o la situación del súbdito, éste se encuentra legitimado para resistirlo. Lo anterior podría parecer de sentido común, y escasamente novedoso: de algún modo, toda una tradición filosófica anterior había defendido el derecho a resistencia legítima en ciertas circunstancias. Sin embargo, lo original de Hobbes es el haber incluido, dentro de quienes detentan este derecho a resistir al soberano, a los culpables justamente condenados en un juicio ${ }^{62}$.

Esto podrá parecer extraño, pero no lo es si se asumen las premisas antropológicas hobbesianas. Más bien: son una consecuencia necesaria de ellas. En efecto: si el Estado se constituye para preservar la seguridad del individuo, y además éste por necesidad desea aquello que es bueno para sí, y la vida es condición del goce de cualquier bien, entonces es sicológicamente imposible que un condenado a muerte

${ }^{56}$ El capítulo XXVII del Leviathan, que trata sobre los delitos, se llama "Of crimes, excuses, and extenuations". Véase, igualmente, el claro pasaje siguiente de Lev. XXVII, p. 470: "The Degrees of Crime are taken on divers Scales, and measured, First, by the malignity of the Source, or Cause: Secondly, by the contagion of the Example: Thirdly, by the mischiefe of the Effect; and Fourthly, by the concurrence of Times, Places, and Persons". La primera medida del castigo es la malicia del agente.

${ }^{57}$ Véase: Lev. XXVII, p. 456.

${ }^{58}$ Ibíd., p. 456.

${ }^{59}$ Ibíd., p. 464.

${ }^{60}$ Ibíd., p. 468.

${ }^{61}$ Véase: Lev. XXVIII, p. 492.

${ }^{62}$ Véase, como ejemplo de la tradición anterior, lo que dice Thoma Aquinat., Summa Theologiae, II-II, q, 69, a. 4, resp., a propósiuto de la pregunta sobre si el condenado a muerte puede resistirse a la imposición de su condena: "aliquis damnatur ad mortem dupliciter. Uno modo, iuste. Et sic non licet condemnato se defendere, licitum enim est iudicieum resistentem impugnare; unde relinquitur quod ex parte eius sit bellum iniustum. Unde indubitanter peccat. Alio modo condemnatur aliquis iniuste. Et tale iudicium simile est violentiae latronum, secundum illud Ezech. XXII, principes eius in medio eius quasi lupi rapientes praedam ad effundendum sanguinem. Et ideo sicut licet resistere latronibus, ita licet resistere in tali casu malis principibus, nisi forte propter scandalum vitandum, cum ex hoc aliqua gravis turbatio timeretur": 
se deje matar por mor de la justicia ${ }^{63}$. Lo que es justo se reduce, en definitiva, a lo que sirve al individuo. De ahí que pueda decir, simultáneamente, y sin caer en incoherencias, que el soberano obra legítimamente al castigar al delincuente, y el delincuente, al resistir el castigo. Con la importante diferencia de que el soberano tiene más poder y terminará imponiéndose, lo cual redundará en beneficio de todos los sujetos distintos del delincuente.

El derecho a resistir el castigo es, así, el mismo derecho a todo que tenía el sujeto en el estado de naturaleza. Así como dicho derecho, en el caso del soberano, adquiría la forma del derecho a castigar, así, en el caso del condenado, una vez desaparecidos los límites que a tal derecho imponía un contrato que ya no puede entenderse como aceptado por el sujeto, adquiere la forma del derecho a resistir ${ }^{64}$. Una vez instituida una comunidad política, el derecho a todo original sólo puede adquirir dos modos: el derecho a castigar, y el derecho a resistir el castigo.

\section{El TRATAMiENTO DEL ENEMigo INTERNO}

Por último, el tratamiento que se debe dar al enemigo interno no cae bajo el ámbito del derecho penal. Con la misma rigurosidad con la que ha procedido a deducir los principios que regirán el castigo en la república a partir de sus supuestos filosóficos fundamentales, Hobbes llegará a la conclusión de que, quienes se opongan activamente a la autoridad del soberano, no deben ser tratados como criminales -el criminal es súbdito-, sino como enemigos. No existe algo así como un derecho penal del enemigo. A terroristas y rebeldes se los enfrenta con el ejército $^{65}$ : "la inflicción de cualquier mal a un hombre Inocente que no sea súbdito, si

${ }^{63}$ Lev. XIV, p. 202: "Whensoever a man Transferreth his Right, or Renounceth it; it is either in consideration of some Right reciprocally transferred to himselfe; or for some other good he hopeth for thereby. For it is a voluntary act; and of the voluntary acts of every man, the object is some Good to himselfe. And therefore there be some Rights, which no man can be understood by any words, or other signes, to have abandoned, or transferred. As first a man cannot lay down the right of resisting them, that assault him by force, to take aways his life; because he cannot be understood to ayme thereby, at any Good to himselfe, The same may be sayd of Wounds, and Chayns, and Imprisonment; both because there is no benefit consequent to such patience; as there is to the patience of suffering another to be wounded, or imprisoned: as also because a man cannot tell, when he seeth men proceed against him by violence, whether they intend his death or not".

${ }^{64}$ Lev. XIV, p. 214: "A Covenant not to defend my selfe from force, by force, is always voyd. For (as I have shewed before) no man can transferre, or lay down his Right to save himself from Death, Wounds, and Imprisonment, (the avoyding whereof is the onely End of laying down any Right;) and therefore the promise of not resisting forece, in no Covenant transferreth any right; nor is obliging-For though a man may Covenant thus, Unlesse I do so, or so, kill me; he cannot Covenant thus, Unlesse I do so, or so, I will not resist you, when you come to kill me. For man by nature chooseth the lesser evil, which is danger of death in resisting; rather than the greater, which is certain and present death in not resisting. And this is granted to be true by all men, in that they lead Criminals to Execution, and Prison, with armed men, nothwithstanding that such Criminals have consented to the Law, by which they are condemned". Nótese que Hobbes dice que los criminales "han consentido" en la ley por la que son condenados: no que "consienten". El consentimiento actual es imposible, y el pasado, es irrelevante para exigir obediencia al criminal.

${ }^{65}$ Así, Hobbes no hubiese podido suscribir las siguientes palabras de JAKOBS, Günter, Feindstrafrecht? Eine Untersuchung zu den Bedingungen von Rechtlichkeit, en Onlinezeitschrift 
es para beneficio de la república, y sin violación de ningún pacto previo, no es una violación de la ley de la naturaleza. Pues todos los hombres que no son súbditos, o son enemigos, o bien han dejado de serlo por medio de pactos precedentes. Pero contra enemigos a quienes la república juzgue capaces de dañarla, es legítimo hacer la guerra por el derecho de naturaleza original" ${ }^{\circ 6}$. Nótese: el soberano está legitimado incluso para atacar preventivamente al enemigo interno: tal como en el estado de naturaleza se justificaba el ataque preventivo, así se justifica, por el mismo derecho de naturaleza operativo en el estado de naturaleza y dejado intacto al soberano, el ataque preventivo contra enemigos internos, vgr., el asesinato selectivo de terroristas ${ }^{67}$.

für Höchstrichterliche Rechtsprechung im Strafrecht, 8-9 (2006) [disponible en http://www. hrr-strafrecht.de/hrr/archiv/06-08/hrrs-8-06.pdf, p. 293], relativas al tratamiento del enemigo interno, mediante el derecho penal del enemigo "Jeder, der zumindest einigermassen verlässlich Rechtstreue verspricht, hat den Anspruch, als Person im Recht behandelt zu werden. Wer dieses Verprechen nicht in glaubhafter Weise leistet, wird tendenziell fremdverwaltet: ihm werden Rechte genommen. Seine Pflichten bleiben ungeschmäler [...]"; p. 294: "[...] das Feindstrafrecht bleibt doch insoweit Recht, als es die Bürger ihrerseits, genauer, den Staat, seine Organe und Funktionäre, bei der Bekämpfung der Feinde bindet. Feindstrafrecht isteben kein Regelwerk zur grenzenlosen Vernichtung, sondern ist im klug verwalteten Rechtstaat eine ultima ratio, die bewusst als Ausnahme angewandt wird [...]". Hobbes, en cambio cree que, cuando alguien resiste activamente la autoridad del soberano -y, por implicación, del derecho-, éste se pone fuera de la república -en lo que conviene con Jakobs-, y por ello deja de tener obligaciones jurídicas respecto de ella, lo mismo que el soberano deja de estar obligado a tratarlo como ciudadano. De ahí no sólo "se le quiten derechos", sino que deja de ser sujeto de cualquier derecho. Precisamente por eso, la república está legitimada para exterminarlos, con los únicos límites, no jurídicos, puestos por la ley de la misericordia, la única que vale en el estado de guerra. No hay un tratamiento jurídico diferenciado respecto de terroristas y rebeldes: "inter arma enim silent leges." Por todo lo anterior, es inducente a error la mención a Hobbes, hecha por el mismo Jakobs -ibíd., p. 293-, como uno de los antecesores -junto a Kant y Fichte- de su "derecho penal del enemigo".

${ }^{66}$ Lev. XVIII, p. 494.

${ }^{67}$ Así, si Hobbes hubiese sido estadounidense, hubiese apoyado sin reservas la "guerra de los drones" contra los terroristas. Con todo, su defensa de la misma hubiese sido distinta de la realizada por la Casa Blanca. Ténganse presente las siguientes declaraciones del presidente George W. Bush: "For centuries, international law recognized that nations need not suffer an attack before they can lawfully take action to defend themselves against forces that present an imminent danger of attack [...]. The United States has long maintained the option of preemptive actions to counter a sufficient threat to our national security. The greater the threat, the greater is the risk of inaction -and the more compelling the case for taking anticipatory action to defend ourselves, even if uncertainty remains as to the time and place of the enemy's attack. To forestall or prevent such hostile acts by our adversaries, the United States will, if necessary, act preemptively": The National Security Strategy of the United States of America, 17 de septiembre de 2002, en http://merln.ndu.edu/whitepapers/USnss2002.pdf, p. 19. Para Hobbes, el ataque preventivo a terroristas se justifica no por el Derecho internacional, que él considera que no es verdadero derecho, sino por el derecho de naturaleza a realizar cualquier cosa que sea necesaria para defenderse. 


\section{Conclusiones:}

COHERENCIAS E INCOHERENCIAS

EN LA DOCTRINA PENAL HOBBESIANA

Distintos han sido los juicios que se han emitido sobre la doctrina penal de Hobbes. Así, mientras algunos lo consideran un liberal y adelantado a su tiempo ${ }^{68}$, otros lo consideran un mero utilitarista ${ }^{69}$. Y es que en la exposición hobbesiana del derecho penal se combinan aspectos que parecen contradictorios y que son valorados actualmente de modo muy diverso: se defiende la necesidad de aplicar tanto castigo cuanto sea necesario para disuadir y, al mismo tiempo, se defiende la obligación de perdonar cuando sea posible; se defiende el principio "nullum crimen sine lege", pero no el "nulla poena sine lege"; se menciona, si no defiende explícitamente, la tortura como uno de los castigos legítimos, al tiempo que se la rechaza como medio probatorio en juicio; se defiende la obligación del soberano de castigar cuando se den ciertas circunstancias, y el derecho del justamente condenado a resistir tal castigo; acepta que el castigo exige culpabilidad en el agente, pero su noción de culpabilidad excluye la idea de posibilidad de actuar de un modo distinto a como efectivamente se actuó.Y, por si fuera poco, rechaza las teorías absolutas de la pena por considerarlas "crueles", y defiende la necesidad de castigar las violaciones a la ley natural.

Hemos querido mostrar cómo tales afirmaciones se derivan de supuestos antropológicos más generales. Así, la doctrina penal hobbesiana podrá parecer a muchos extraña, pero a quien acepte tales supuestos le parecerá absolutamente razonable.

Por supuesto, podemos afirmar que tales supuestos antropológicos son incompatibles entre sí (y, por ende, no aceptarlos todos). El determinismo materialista y el egoísmo sicológico son, cada uno de ellos, incompatibles con la creencia en algo así como una obligación moral o con la idea de culpabilidad en general. De ellos se derivan dos visiones contrapuestas e incompatibles del hombre: como agente moral susceptible de reproche, y como mero agente racional necesariamente egoísta. La primera visión aparece nítidamente cuando Hobbes trata el tema de la culpabilidad y las eximentes de responsabilidad penal; la segunda, cuando trata el tema de la determinación de la cuantía de la pena. Hay, así, incoherencias en

${ }^{68}$ Ristroph, Alice, Criminal Law for Humans, en Dyzenhaus, David - Poole, Thomas (editores), Hobbes and the Law (Cambridge, Cambridge University Press, 2012), p. 98: "Both the familiar content of Hobbes' criminal law theory and his more surprising claims about punishment are, I suggest, the product of his unwavering attention to the humanity of the various persons who make, break and enforce the criminal law. His criminal law addresses and sometimes accommodates human frailty, but as or more importantly, it also reveals a commitment to equal human dignity".

${ }^{69}$ CatTANeO, cit. (n. 19), p. 139: "[...] l'illuminismo penale è soprattutto caratterizzato da un fondamentale umanitarismo (pensiamo soltanto a Beccaria), che è totalmente assente dal pensiero di Hobbes; quest' ultimo può giungere, come giungerà anche Bentham, a certe soluzioni vicine a quelle illuministiche, ma per una via che non è quella dell'umanità e dei diritti della persona, bensì quella dell'utilitarismo e di un razionalismo empírico". 
la doctrina penal de Hobbes, en cuanto hay incoherencias más fundamentales en su pensamiento filosófico.

\section{BiBLIOGRAFÍA}

Becker, G., Crime and Punishment: An Economic Approach, en Journal of Political Economy, 76 (1968) 2.

BECKer, G., Nobel Lecture: The Economic Way of Looking at Behavior, en The Journal of Political Economy, 101 (1993) 3.

Bobbio, N., La teoria politica di Hobbes (1980), después en El Mismo, Thomas Hobbes (Torino, 2004).

Brown, S., Hobbes: the Taylor Thesis, en The Philosophical Review, 68 (1959) 3.

Cattaneo, M., Hobbes e il fondamento del diritto di punire, en Sorgi, G. (editor), Politica e Diritto in Hobbes (Milano, 1995).

Damrosch JR., L., Hobbes as Reformation Theologian: Implications of the Free-Will Controversy, en Journal of the History of Ideas, 40 (1979) 3.

Foisneau, L., Hobbes et la toute-puissance de Dieu (Paris, 2000).

ForTier, John, "A Discourse of Laws": The Perils of Wordprint Analysis, en The Review of Politics, 59 (1997) 4.

HaRT, H.L.A, The Concept of Law (Oxford, 1994).

Hermosa Andújar, A., La doctrina penal de Hobbes, en Fragmentos de Filosofía, 6 (2008).

HobBes, Th., De Cive (Oxford, 1983).

Hobbes, Th., Elements of Law. Human Nature and De Corpore Politico (New York, 2008).

HoввеS, Th., Leviathan (Oxford, 2012).

HobBes, Th., Of Liberty and Necessity, en Chappel, V. (editor), Hobbes and Bramhall on Liberty and Necessity (Cambridge, Kindle, 2003).

HobBes, Th., Three Discourses: A Critical Modern Edition of Newly Identified Work of the Young Hobbes (edición de Noel Reynolds y Arlene Saxenhouse, Chicago, 1995).

JаковS, G., Feindstrafrecht? Eine Untersuchung zu den Bedingungen von Rechtlichkeit, en Onlinezeitschrift für Höchstrichterliche Rechtsprechung im Strafrecht 8-9 (2006) [disponible en http://www.hrr-strafrecht.de/hrr/archiv/06-08/hrrs-8-06.pdf].

Martinich, A., The Two Gods of Leviathan. Thomas Hobbes on Religion and Politics (Cambridge, 1992).

RHONHeImer, M., La filosofía politica di Thomas Hobbes (Roma, 1997).

Ristroph, A., Criminal Law for Humans, en Dyzenhaus, D. - Poole, Th. (editores), Hobbes and the Law (Cambridge, 2012).

SAdler, G., The Laws of Nature as Moral Norms in Hobbes' Leviathan, en Acta Philosophica, 15 (2006) 1.

Schrock, Th., The Rights to Punish and Resist Punishment in Hobbes's Leviathan, en The Western Political Quarterly, 44 (1991) 4.

Strauss, L., Hobbes' politische Wissenschaft und zugehörige Schriften (Stuttgart, 2008).

TAYLOR, A. E., The Ethical Doctrine of Hobbes, en Philosophy, 13, 52 (1938).

The National Security Strategy of the United States of America [en http://merln.ndu. edu/whitepapers/USnss2002.pdf]. 
Thoma Aquinat., Summa Theologiae [disponible en www.corpusthomisticum.org]. Weber, D., Hobbes et le corps de Dieu (Paris, 2009).

ZAGORIN, P., Hobbes and the Law of Nature (Princeton, 2009).

Zarka, Y., La Décision métaphysique de Hobbes. Conditions de la politique (Paris, 2009). 